\title{
CLASSIFICAÇÃO AMBIENTAL DOS FRAGMENTOS FLORESTAIS DA ÁREA RURAL DO MUNICÍPIO DE MARINGÁ-PR, BRASIL: PRIMEIRAS ETAPAS
}

\author{
André Cesar Furlaneto Sampaio* \\ Paulo José Moraes Monteiro e Teixeira Germano** \\ Bruno Luiz Domingos De Angelis*** \\ Maicon José Nocchi****
}

RESUMO: O Estado do Paraná sofreu grande degradação de suas florestas, sendo a Floresta Estacional Semidecidual a mais afetada. Essa degradação ocasionou uma fragmentação florestal que causa prejuízos para a biodiversidade e o equilíbrio ambiental. O presente artigo demonstra a metodologia e os resultados das primeiras etapas de um protocolo para avaliar a qualidade dos remanescentes florestais nativos na área rural do município de Maringá-PR, Brasil. O protocolo visa ser uma ferramenta para determinações de políticas públicas de conservação ambiental, classificando os remanescentes florestais (fragmentos) em níveis de importância para conservação ambiental. No presente trabalho, se quantificou e qualificou por meio de sensoriamento remoto, cálculo de índices e métricas da paisagem, e avaliação de atributos físicos e biológicos todos os fragmentos. Verificou-se uma área rural com cobertura florestal de $9,81 \%$, constituída por 161 fragmentos, sendo a maioria pequenos (menores que $50 \mathrm{ha}$ ) e com baixa conectividade.

PALAVRAS-CHAVE: Fragmentação florestal; Floresta Estacional Semidecidual; Ecologia da Paisagem; Maringá.

\section{ENVIRONMENTAL CLASSIFICATION OF FOREST FRAGMENTS IN THE RURAL AREA OF MARINGÁ, BRAZIL: FIRST STEPS}

ABSTRACT: The Brazilian state of Paraná has undergone extensive forest degradation,

\footnotetext{
Doutorado em Geografia pela Universidade Estadual de Maringá. Docente no Centro Universitário de Maringá - UNICESUMAR, Maringá (PR), Brasil. E-mail: sampaio.floresta@gmail.com

** Mestre em Engenharia Urbana pela Universidade Estadual de Maringá. Docente no departamento de Geografia na Universidade Estadual de Maringá - UEM, Maringá (PR), Brasil.

${ }^{* * *}$ Docente Associado do Departamento de Agronomia da Universidade Estadual de Maringá. Docente e orientador do Programa de Pós-Graduação em Geografia/UEM e do Programa de Pós-Graduação em Engenharia Urbana/UEM, Maringá (PR), Brasil.

${ }^{* * * *}$ Docente no Estado do Mato Grosso do Sul; Mestrando em Ciências Biológicas na Universidade Federal de Mato Grosso do Sul - UFMS, Brasil.
} 
with great consequences to the semideciduous seasonal forest. Degradation caused forest fragmentation that jeopardized biodiversity and environmental equilibrium. Current paper shows methodology and results of the first stages in a protocol to assess native forest remnants in the rural area of the municipality of Maringá PR Brazil. The protocol is a tool for public policies in environmental conservation, classifying forest remnants at levels of importance for environmental conservation. All forest fragments were quantified and qualified by remote sensing, index calculation, environment metrics and evaluation of physical and biological attributes. A rural area with 9.81 forest cover, formed by 161 fragments, most of which less than 50 ha and low connectivity was analyzed.

KEY WORDS: Forest fragments; Semideciduous seasonal forest; Landscape ecology; Maringá.

\section{INTRODUÇÃO}

O Paraná apresentava originalmente uma cobertura vegetal predominantemente florestal, que ocupava grande parte da sua extensão territorial. No entanto, em décadas de exploração intensa e contínua foram suficientes para modificar esta paisagem. Em 2012, constatou-se em levantamento realizado pelo Instituto Nacional de Pesquisas Espaciais (INPE) e Fundação SOS Mata Atlântica que restam somente $11,84 \%$ da cobertura nativa que existia originalmente no Estado (SOS MATA ATLÂNTICA; INPE, 2012).

As atividades de extração madeireira, expansão agrícola extensiva, ampliação de plantios florestais exóticos homogêneos, além da expansão urbana, são pressões que indicam ainda nos dias atuais uma tendência de redução e descaracterização contínua das florestas e outras fisionomias vegetais paranaenses. Consolidam-se assim inúmeros processos prejudiciais ao meio ambiente e ao próprio ser humano, como erosão, deslizamentos, assoreamento de cursos d'água, perda de fertilidade do solo, alterações microclimáticas, proliferação de pragas e espécies exóticas, fragmentação florestal, desertificação, extinção de espécies nativas, entre vários outros, tanto de cunho ambiental quanto social (BLUM; OLIVEIRA, 2003).

Todos os ecossistemas florestais encontrados no Paraná foram degradados. 
Restando aproximadamente $0,8 \%$ da cobertura original do Paraná com floresta ombrófila mista (CASTELLA; BRITEZ, 2004), cerca de 2\% da cobertura da Floresta Estacional Semidecidual (FES) (WILLIS, 1979; BIERREGAARD; LOVEJOY, 1988; DURIGAN et al., 2000) e cerca de 7,73\% da floresta ombrófila densa (FUNDAÇÃO SOS MATA ATLÂNTICA; INPE, 2009).

A FES foi o ecossistema florestal mais rápido e extensamente devastado no Estado do Paraná e em toda a sua área de ocorrência natural. A expansão da atividade agrícola iniciada no norte do Paraná, a partir de 1920, em função da boa fertilidade do solo, trouxe a devastação da FES, que rapidamente foi reduzida a pequenos e esparsos fragmentos florestais. Dos fragmentos remanescentes, poucos têm área representativa e encontram-se preservados. Um dos principais problemas ocasionados por esta fragmentação intensa é a extinção de espécies, que têm sido frequentemente documentada no Brasil e no mundo (WILLIS, 1979; BIERREGAARD; LOVEJOY, 1988; DURIGAN et al., 2000).

Maringá foi um dos municípios, nos domínios da FES, que teve sua área florestal mais devastada, estando atualmente entre os municípios com menor área florestal do Estado, tendo apenas 3\% de sua cobertura original de florestas nativas (FUNDAÇÃO SOS MATA ATLÂNTICA; INSTITUTO NACIONAL DE PESQUISAS ESPACIAIS, 2009).

Fragmentação, degradação e perda de habitat representam as ameaças mais significativas à estrutura e persistência de populações de animais e suas comunidades (SAUNDERS et al., 1991; FAHRIG, 2003). Manchas isoladas de habitats nativos muitas vezes suportam pequenas populações que recebem pouca ou nenhuma imigração, aumentando a probabilidade de extinção (FAHRIG; MERRIAM, 1994).

Pode-se entender um fragmento florestal como sendo uma unidade física da paisagem, ou seja, um elemento fundamental de estudo para o entendimento da paisagem como um todo. Para se fazer o estudo da paisagem com toda sua heterogeneidade e tipos de abordagens (geográficas e ecológicas) entra-se em uma área de conhecimento intitulada de ecologia de paisagem (METZGER, 2001).

Atualmente vários estudos em ecologia de paisagem têm maior aplicabilidade e agilidade, pois os recursos tecnológicos colaboram na obtenção de dados e informações; comumente utilizam-se imagens de satélite, fotografias aéreas, 
técnicas de geoprocessamento e outros. Esse arcabouço técnico traz subsídios tanto para o estudo das interações (reflexo/consequência) do homem com o ambiente, quanto para compreender os processos ecológicos nas paisagens e suas unidades e elementos. A aplicação da ecologia de paisagem está relacionada com o planejamento da ocupação territorial, incluindo paisagens naturais e culturais, no manejo de recursos naturais e na conservação da diversidade biológica (METZGER, 2001).

Estudos sobre a situação das florestas em paisagens fragmentadas são importantes para entender a gravidade desse problema e de como traçar diretrizes políticas e projetos para mitigar e compensar os danos ambientais, assim como para recuperar os ecossistemas. São poucos os registros históricos detalhados das espécies vegetais e animais que existiam antes de toda expansão urbana e das atividades agrossilvipastoris, ou seja, estudos dos remanescentes florestais se tornam cruciais para futuras comparações científicas e quantificações das perdas ambientais (MATOS, 2006).

Nesse contexto, o presente artigo vem colaborar no preenchimento de uma lacuna nos estudos relacionados ao processo de degradação da FES, focando seu estudo na área rural do município de Maringá. Os resultados irão colaborar no direcionamento de ações e medidas para a melhora da qualidade ambiental na paisagem deste município e região.

$\mathrm{O}$ artigo faz parte dos resultados das primeiras etapas do desenvolvimento de um protocolo (metodologia) de avaliação da qualidade de remanescentes florestais na área rural do município de Maringá. Os resultados das últimas etapas serão publicados em um artigo posterior. O protocolo em construção visa indicar os remanescentes florestais (fragmentos) prioritários para conservação na região, em busca de melhorar as interações ecológicas na paisagem. Para isso o estudo em questão utilizou-se de um detalhamento da situação de conservação ambiental dos fragmentos mais relevantes, tanto por meio de sensoriamento remoto como in loco. Pretende-se que os resultados funcionem como uma ferramenta para determinações de políticas públicas de conservação ambiental. 


\section{MATERIAL E MÉTODOS}

O protocolo de avaliação proposto se divide em quatro etapas: quantificar os fragmentos florestais existentes na área rural do município de Maringá; (2) determinar os fragmentos fontes existentes na área rural do município; (3) qualificar e classificar os fragmentos florestais em relação aos índices e métricas da paisagem; (4) qualificar e classificar os fragmentos fontes identificados in loco. Neste artigo constam os métodos e resultados da realização das primeiras etapas do desenvolvimento desse protocolo (Etapas 1, 2 e 3).

\section{1 ÁREA DE ESTUDO}

O município de Maringá (Figura 1) possui uma área de $489,76 \mathrm{~km}^{2}$, e localizase na região Sul do Brasil, região Norte Central paranaense, mais precisamente no terceiro planalto, entre as coordenadas $23^{\circ} 25^{\prime} \mathrm{S}$ e $51^{\circ} 57^{\prime} \mathrm{O}$, sendo cortado ao sul pela linha imaginária do Trópico de Capricórnio (BARROS, et al., 2004). 

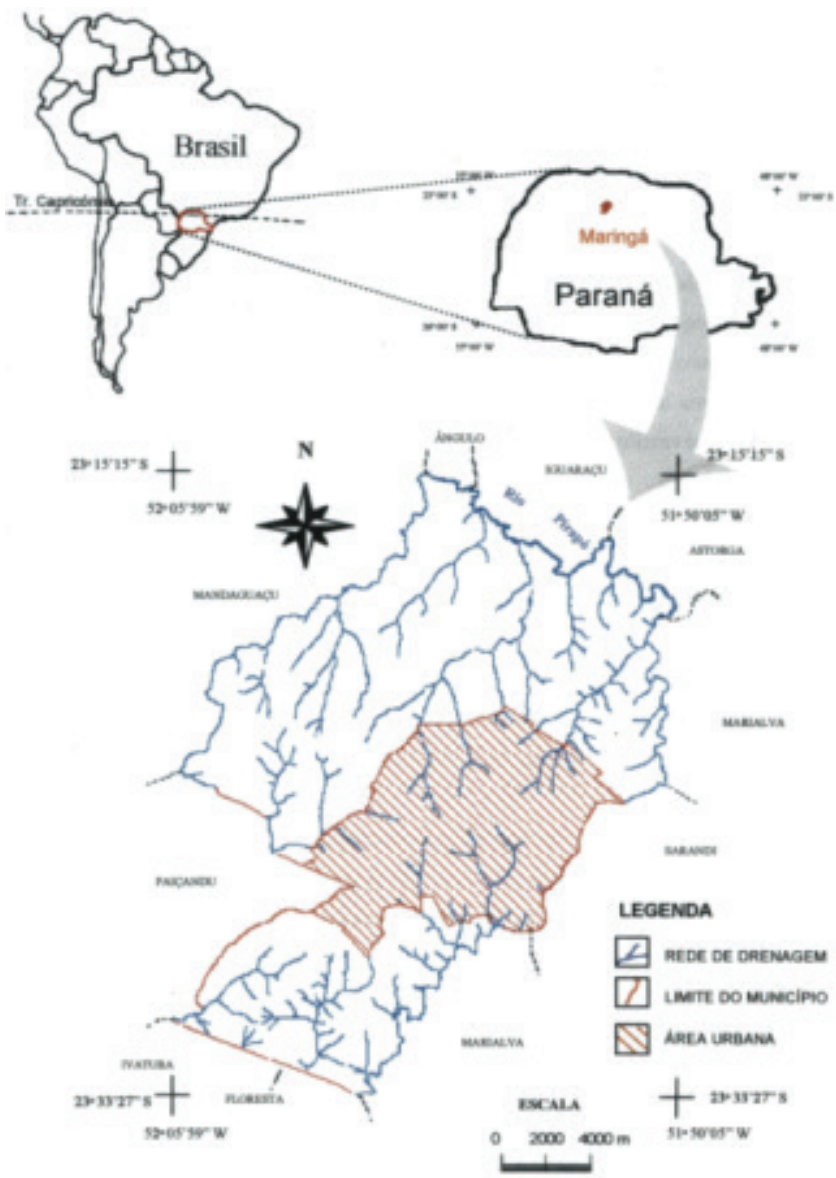

Figura 1. Localização do município de Maringá-PR e de sua área urbana e rural. Fonte: Barros et al. 2004

\subsection{MATERIAIS UTILIZADOS}

Foi utilizada uma imagem de satélite, fornecida gratuitamente pelo Instituto Nacional de Pesquisas Espaciais (INPE), após requerimento, por meio do site http:// www.dgi.inpe.br/CDSR/: Landsat 5, sensor TM, referente à órbita 222, ponto 76, bandas TM1, TM2, TM3, TM4 e TM5, de 24/09/2008. A solicitação foi feita após análise das melhores imagens que recobriam a área de estudo sem interferência de nuvens e com resolução mínima de 30 metros (resolução mínima viável). 
Os softwares utilizados para o processamento das imagens de satélite e cálculos de índices e métricas da paisagem foram: ENVI 4.5 - software para visualização, exploração, análise e apresentação de dados na área de Sensoriamento Remoto/SIG, desenvolvido pela ITTVIS (http://www.ittvis.com/), comercializado e com assessoria técnica no Brasil pela empresa Sulsoft (http://www.envi.com.br/); Fragstats 3.3 - software de domínio público que calcula a estrutura da paisagem usando mais de 50 métricas da paisagem. Foi desenvolvido por Kevin McGarigal e Barabara J. Marks, na "Oregon State University". Pode ser baixado através do site http://www.umass.edu/landeco/research/fragstats/downloads/fragstats_downloads. html; e AutoCAD - software para desenho auxiliado por computador - criado e comercializado pela Autodesk, Inc. desde 1982.

\subsection{METODOLOGIA}

Inicialmente no software ENVI 4.5 realizou-se um georreferenciamento e recorte das imagens de satélite com a utilização de um vetor em formato dxf fornecido pela prefeitura municipal de Maringá (SAD 69). O vetor detinha os limites da área rural e urbana de Maringá. O método utilizado foi de associação de pontos de controle imagem e vetor. Após esses trabalhos, a imagem teve subdividida a área rural em dois recortes, norte e sul. Isso facilitou o processo de definição do uso do solo, que focou a localização e tamanho dos remanescentes florestais. Em cada recorte (norte e sul) da imagem foi executada uma classificação orientada a objeto e supervisionada, através do software ENVI 4.5.

A primeira fase dessa classificação foi a segmentação das imagens, executada a partir da função Feature Extraction, presente nas funções do módulo ENVI ZOOM do programa. A segmentação é um processo de particionamento da imagem em segmentos, que ocorre por meio do agrupamento de pixels vizinhos que contenham similaridade em suas feições (brilho, textura, cor, entre outras). Foram testados vários níveis de segmentação e escolhido o que proporcionou maior visibilidade e confiabilidade na divisão de segmentos da vegetação florestal.

Após a segmentação foi feita uma extração de feições de interesse, que consistiu na seleção de segmentos da imagem como amostras representativas 
das classes de interesse: matriz - áreas não florestais (culturas, pastagens, água, edificações, estradas, entre outras); e áreas florestais (florestas comerciais ou nativas de qualquer estágio sucessional). Foram testadas inúmeras seleções de segmentos até que se atingiram resultados satisfatórios de classificação.

A classificação foi exportada pelo software ENVI 4.5 em formato dxf (arquivo vetorial) para ser trabalhado no software AutoCAD, neste foram excluídos os fragmentos menores que 04 hectares, atitude tomada com fins de diminuir erros de interpretação da imagem, pela baixa resolução.

$\mathrm{O}$ arquivo vetorial trabalhado foi então convertido pelo software ENVI 4.5 em arquivo raster (ASCII) e este foi trabalhado no software Fragstat, onde foram calculados os índices e métricas da paisagem definidos para essa pesquisa.

As métricas e índices da paisagem utilizados neste estudo foram escolhidos em função do objetivo do estudo: quantificação e qualificação adequada dos remanescentes florestais da paisagem (Tabela 1).

Quadro 1. Índices e métricas da paisagem selecionados para a pesquisa

(Continua)

\begin{tabular}{|c|c|c|l|l|}
\hline Sigla & Nome & Escala & \multicolumn{1}{c|}{ Descrição } & Referência \\
\hline NP & $\begin{array}{l}\text { Número de } \\
\text { fragmentos }\end{array}$ & Classe & $\begin{array}{l}\text { Número de fragmentos } \\
\text { da classe correspondente } \\
\text { (Florestas) }\end{array}$ & $\begin{array}{l}\text { McGarigal e Marks } \\
(1995)\end{array}$ \\
\hline P\%LAND & $\begin{array}{c}\text { Porcentagem } \\
\text { fragmentos }\end{array}$ & Classe & $\begin{array}{l}\text { Porcentagem da paisagem } \\
\text { coberta por fragmentos } \\
\text { florestais }\end{array}$ & Volotão (1998) \\
\hline C\%LAND & $\begin{array}{c}\text { Porcentagem áreas } \\
\text { centrais }\end{array}$ & Classe & $\begin{array}{l}\text { Percentual de áreas } \\
\text { centrais (excluídas as } \\
\text { bordas de 30 metros) em } \\
\text { relação à área total da } \\
\text { paisagem. }\end{array}$ & Volotão (1998) \\
\hline ÁREA & Área (ha) & Fragmento & $\begin{array}{l}\text { Área total de um } \\
\text { fragmento }\end{array}$ & $\begin{array}{l}\text { McGarigal e Marks } \\
\text { (1995) }\end{array}$ \\
\hline
\end{tabular}


(Conclusão)

\begin{tabular}{|c|c|c|c|c|}
\hline Sigla & Nome & Escala & Descrição & Referência \\
\hline SHAPE & Índice de forma & Fragmento & $\begin{array}{l}\text { Perímetro }(\mathrm{m}) \text { dividido } \\
\text { pela raiz quadrada da } \\
\text { área }(\mathrm{m} 2) \text { do fragmento, } \\
\text { ajustado por uma } \\
\text { constante para ter-se a } \\
\text { equivalência a um círculo } \\
\text { padrão. }\end{array}$ & $\begin{array}{l}\text { McGarigal e Marks } \\
(1995)\end{array}$ \\
\hline FRACT & $\begin{array}{l}\text { Índice de forma na } \\
\text { dimensão fractal }\end{array}$ & Fragmento & $\begin{array}{l}\text { Igual a duas vezes o } \\
\text { logaritmo do perímetro } \\
(\mathrm{m}) \text { do fragmento } \\
\text { dividido pelo logaritmo } \\
\text { da área do fragmento. } \\
\text { Valores próximos a } 1 \\
\text { indicam fragmentos de } \\
\text { forma regular e valores } \\
\text { próximos a } 2 \text { indicam } \\
\text { formas irregulares, com } \\
\text { alta proporção perímetro } \\
\text { área. }\end{array}$ & $\begin{array}{l}\text { McGarigal e Marks } \\
(1995)\end{array}$ \\
\hline CORE & Área nuclear (ha) & Fragmento & $\begin{array}{l}\text { Área }(\mathrm{m} 2) \text { interna de um } \\
\text { fragmento, após ter sido } \\
\text { retirada a faixa referente } \\
\text { ao efeito de borda }(30 \\
\text { m), dividida por } 10.000 \\
\text { (para converter em } \\
\text { hectares). }\end{array}$ & $\begin{array}{l}\text { McGarigal e Marks } \\
(1995)\end{array}$ \\
\hline ISG & $\begin{array}{l}\text { Isolamento ao } \\
\text { fragmento fonte } \\
\text { mais próximo }\end{array}$ & Fragmento & $\begin{array}{l}\text { É a distância de um } \\
\text { fragmento "f" estudado } \\
\text { ao fragmento fonte mais } \\
\text { próximo. Este fragmento } \\
\text { "fonte" pode ser um } \\
\text { grande maciço florestal } \\
\text { ou reserva legal, ou } \\
\text { fragmento acima de } \\
\text { um determinado limiar } \\
\text { (considerando ter uma } \\
\text { população estável de } \\
\text { espécies ou espécie em } \\
\text { estudo). }\end{array}$ & $\begin{array}{l}\text { Lynch e Whigham } \\
(1984) ; \text { Van Dorp } \\
\text { e Opdam (1987); } \\
\text { verboom e Van } \\
\text { Apeldoorn (1990) apud } \\
\text { Metzger (2003) }\end{array}$ \\
\hline
\end{tabular}


Para a qualificação dos remanescentes se optou por uma adaptação da metodologia de Durigan et al. (2006), que formularam a metodologia para seleção de fragmentos de cerrado prioritários para a formação de unidades de conservação.

Primeiramente foram classificados como de maior importância os fragmentos com maior área núcleo (core), tanto do setor norte como do sul. Essa qualificação se deu pelo fato de que fragmentos de maior extensão de área podem suportar quantidade suficiente de indivíduos de espécies de forma a manter as populações em longo prazo. Além disso, podem atuar como áreas fontes de espécies para demais fragmentos favorecendo o processo de recolonização de áreas. Os efeitos de borda, nessas áreas centrais maiores, tendem a ser menores, pois as áreas centrais dos fragmentos ficam mais distantes das áreas periféricas do fragmento (WANDEMBRUCK et al., 2007).

Os fragmentos de maior área núcleo (core) existentes no setor norte e no setor sul distintamente foram então designados como fragmentos "fonte", ou seja, considerados como prováveis possuidores de uma população estável de espécies, considerando a realidade da paisagem em questão.

Foram determinados indicadores para o estado de conservação dos fragmentos, divididos nos temas: atributos biofísicos, preservação de recursos naturais e influências externas: sendo para atributos biofísicos: tamanho (área total) - áreas maiores têm maiores chances de manter grandes populações de algumas espécies, principalmente grandes carnívoros ou mesmo florestas em melhor estado de conservação (MAC ARTHUR; WILSON, 1967; NOSS; CSUTI, 1997). / Conectividade - áreas com maior probabilidade de fluxo gênico com outros fragmentos naturais importantes foram consideradas de maior valor para a conservação. Levou-se em consideração áreas de remanescentes florestais existentes fora do perímetro do município, pois podem estabelecer importantes conexões para a conservação da biodiversidade local. Associado a conectividade vem o atributo distância do fragmento fonte (BRIERS, 2002; MCCALLUM, 2000 apud DURIGAN et al. 2006 ). / Proteção de mananciais - pela importância dos recursos hídricos e a biodiversidade associada a estes foi determinado maior valor para áreas que protegem nascentes, seguidas daquelas que protegem apenas cursos d'água e com menor valor para áreas que não possuem qualquer corpo d'água dentro de seus limites. / 
Riqueza de espécies lenhosas - quanto maior riqueza de espécies lenhosas menor perturbação do ecossistema e tendência de maior diversidade de fauna. A riqueza de espécies tem sido o critério mais largamente utilizado na seleção de reservas ao redor do mundo (SMITH;THEBERGE, 1986 apud DURIGAN et al., 2006). / Número de espécies raras endêmicas ou em risco de extinção. Segundo Temple (1997), a presença e a persistência de espécies raras em uma comunidade é atualmente um dos mais importantes indicadores da integridade do ecossistema. Espécies em risco de extinção por si só já demonstram valor ecológico. Para preservação da integridade dos recursos naturais: presença de espécies exóticas invasoras - essas espécies são consideradas a segunda maior causa de extinção de espécies no planeta, afetando diretamente a biodiversidade, a economia e a saúde humana (MMA, 2006). / Presença de gado - a presença de gado oferece risco de transmissão de zoonoses à fauna nativa e geralmente prejudica os processos naturais de regeneração das espécies vegetais e a dinâmica do ecossistema (DURIGAN et al., 2006). / Presença de lixo - lixo abundante ou tóxico pode trazer sérias consequências negativas ao ecossistema (DURIGAN et al., 2006). / Evidência do corte de árvores - o corte de árvores, mesmo em corte seletivo, é uma evidência direta de modificações e atuação antrópica no ecossistema. Para influências externas: usos da terra do entorno - as estratégias de conservação devem considerar a qualidade da paisagem como um todo, incluindo a matriz. Atribuiu-se maior valor às áreas cujo entorno é ocupado por atividades que condicionam menor risco de incêndios ou contaminação e que funcionam como extensões de habitat para parte da fauna silvestre, oferecendo abrigo ou alimento (FAHRIG, 2001). / Índices de forma (Shape e Fract). Primack e Rodrigues (2001) afirmam que em relação aos formatos de áreas o ideal é que elas sejam o mais próximo possível ao circular, pois estes minimizam a relação bordaárea, cujo centro encontra-se mais distante das bordas do que qualquer outra forma, especialmente as alongadas.

Para cada indicador selecionado foi atribuído um peso diferente e determinaram-se notas a serem atribuídas a cada indicador (Tabela 1), de acordo com várias classes de qualificação por indicador, respeitando sua importância relativa, estabelecida com base na experiência dos autores desse artigo. 
Tabela 1. Indicadores de conservação biológica selecionados

(Continua)

\begin{tabular}{|c|c|c|c|}
\hline Indicador & Peso & Classe & Nota \\
\hline \multirow{4}{*}{$\begin{array}{l}\text { Área total e área núcleo } \\
\text { do fragmento (CORE) }\end{array}$} & \multirow{4}{*}{4} & Menor que 50 ha & 1 \\
\hline & & 50 a 100 ha & 2 \\
\hline & & 101 a 400 ha & 3 \\
\hline & & maior que 400 ha & 4 \\
\hline \multirow{5}{*}{ Uso do solo do entorno } & \multirow{5}{*}{4} & Urbanização & 1 \\
\hline & & Rodovia ou cana-de-açúcar & 2 \\
\hline & & Agricultura anual & 3 \\
\hline & & Agricultura perene, fruticultura ou pastagem & 4 \\
\hline & & Reflorestamento & 5 \\
\hline \multirow{3}{*}{ Proteção de mananciais } & \multirow{3}{*}{4} & Sem água & 1 \\
\hline & & Protege curso de água & 2 \\
\hline & & Protege nascente & 3 \\
\hline \multirow{4}{*}{ Conectividade } & \multirow{4}{*}{3} & $\begin{array}{l}\text { Nenhum outro fragmento "fonte" (acima de } 100 \\
\text { ha) em um raio de } 7 \mathrm{Km} \text {. }\end{array}$ & 1 \\
\hline & & $\begin{array}{l}\text { Um fragmento "fonte" em um raio de } 7 \mathrm{Km} \text { sem } \\
\text { conexốes próximas }(1 \mathrm{Km}) .\end{array}$ & 2 \\
\hline & & $\begin{array}{l}\text { Um fragmento "fonte" em um raio de } 7 \mathrm{Km} \text { com } \\
\text { conexões próximas }(1 \mathrm{Km}) \text { ou mais de um sem } \\
\text { conexões próximas. }\end{array}$ & 3 \\
\hline & & $\begin{array}{l}\text { Um ou mais fragmentos "fonte" (acima de } 100 \mathrm{ha} \text { ) } \\
\text { em um raio de } 7 \mathrm{Km} \text { e com conexões próximas (1 } \\
\mathrm{Km} \text { ). }\end{array}$ & 4 \\
\hline \multirow{4}{*}{$\begin{array}{l}\text { Riqueza de espécies } \\
\text { lenhosas }\end{array}$} & \multirow{4}{*}{3} & Menos de 50 espécies & 1 \\
\hline & & 51 a 80 espécies & 2 \\
\hline & & 81 a 110 espécies & 3 \\
\hline & & $>110$ espécies & 4 \\
\hline
\end{tabular}


(Conclusão)

\begin{tabular}{|c|c|c|c|}
\hline Indicador & Peso & Classe & Nota \\
\hline \multirow{4}{*}{$\begin{array}{l}\text { Número de espécies } \\
\text { raras, endêmicas ou em } \\
\text { risco de extinção }\end{array}$} & \multirow{4}{*}{3} & Nenhuma espécie & 1 \\
\hline & & Uma ou duas espécies & 2 \\
\hline & & Três ou quatro espécies & 3 \\
\hline & & Mais de quatro espécies & 4 \\
\hline \multirow{4}{*}{$\begin{array}{l}\text { Presença de espécies } \\
\text { exóticas e invasoras }\end{array}$} & \multirow{4}{*}{3} & $\begin{array}{l}\text { Aglomerados e indivíduos distribuídos por toda } \\
\text { a área }\end{array}$ & 1 \\
\hline & & Aglomerados isolados & 2 \\
\hline & & $\begin{array}{l}\text { Esparsas pela área ou em número e espécies } \\
\text { reduzido }\end{array}$ & 3 \\
\hline & & Nenhuma espécie & 4 \\
\hline \multirow{4}{*}{ Índice de forma (Shape) } & \multirow{4}{*}{2} & $>3,5$ & 1 \\
\hline & & $>2$ até 3,5 & 2 \\
\hline & & $>1,5$ até 2 & 3 \\
\hline & & de 1,0 até 1,5 & 4 \\
\hline \multirow{2}{*}{ Presença de gado } & \multirow{2}{*}{2} & Presente & 1 \\
\hline & & Não presente & 2 \\
\hline \multirow{4}{*}{$\begin{array}{l}\text { Distância de fragmento } \\
\text { fonte }\end{array}$} & \multirow{4}{*}{2} & $>4000$ metros & 1 \\
\hline & & 2000 até 4000 metros & 2 \\
\hline & & 1001 até 2000 metros & 3 \\
\hline & & $<1000$ metros & 4 \\
\hline \multirow{2}{*}{ Presença de lixo } & \multirow{2}{*}{1} & Presente & 1 \\
\hline & & Não presente & 2 \\
\hline \multirow{2}{*}{ Evidência de cortes } & \multirow{2}{*}{1} & Presente & 1 \\
\hline & & Não presente & 2 \\
\hline
\end{tabular}

Cada fragmento "fonte" receberá na última etapa de desenvolvimento do protocolo uma avaliação completa, avaliando-se todos os indicadores propostos. O restante dos fragmentos, foco de análise deste artigo, recebeu uma avaliação 
qualitativa baseada nos indicadores que não necessitam de averiguações in loco: tamanho (área total); conectividade (incluindo distância do fragmento fonte), uso da terra do entorno e índices de forma (Shape e Fract) e proteção de manancial.

A qualificação (valor) de cada fragmento para a conservação consistiu no somatório da nota atribuída a cada um dos indicadores, multiplicado pelo peso atribuído ao respectivo indicador. A menor pontuação possível era de 18 pontos e a maior de 72 pontos, entre estas pontuações foi definida uma classificação de prioridades:

Prioridade I-pontuação de 37 até 72 . Considerou-se que de 37 pontos (acima de $50 \%$ da pontuação máxima) até 72 pontos (pontuação máxima) os fragmentos em questão estariam dentro da maior prioridade, sendo os mais importantes para a conservação da qualidade da flora e da paisagem da área rural do município, sendo assim, conclui-se que são onde se deve implementar prioritariamente projetos de ações conservacionistas.

Prioridade II - pontuação de 31 até 36 . Considerou-se que de 31 pontos (acima de 40\% da pontuação máxima) até 36 pontos (cerca de $50 \%$ da pontuação máxima) os fragmentos em questão estariam dentro da segunda maior prioridade, ou seja, não sendo o mais emergencial.

Prioridade III - pontuação de 18 até 30. Considerou-se que de 18 pontos (pontuação mínima) até 30 pontos (cerca de $40 \%$ da pontuação máxima) a prioridade de conservação e para a implementação de atividades para a melhoria das condições ecológicas, dentro da realidade da paisagem rural de Maringá, não são emergenciais, sendo esses os de última prioridade.

\section{RESULTADOS E DISCUSSÕES}

Constatou-se que a área rural de Maringá possui 9,81\% de cobertura florestal (PLAND) constituída por 161 fragmentos florestais. O resultado é diferente do verificado no Atlas da Mata Atlântica (FUNDAÇÃO SOS MATA ATLÂNTICA; INPE, 2009), que constatou apenas 3\% de cobertura florestal no município. Porém, é preciso ressaltar que foram utilizadas metodologias diferentes. Neste trabalho, 
considerou-se a cobertura florestal contabilizando plantios comerciais e vegetação florestal arbórea em todos os estágios de sucessão. No estudo anterior, foram considerados apenas fragmentos de floresta nativa no estágio avançado da sucessão e com mais de 05 hectares de área.

Todos os fragmentos receberam notas conforme a metodologia especificada e foram classificados segundo sua área total, uso do solo no entorno, índices de forma e distância ao fragmento fonte mais próximo. Os resultados demonstram uma classificação de prioridade, indicando uma ordem de importância dos fragmentos para a manutenção da biodiversidade local, sendo a prioridade I aquela com os fragmentos nativos mais importantes, que obtiveram os melhores resultados, a prioridade II sendo intermediária e a prioridade III a com os piores resultados. Além dessas prioridades foram determinados os fragmentos fonte (Figuras 2 e 3 ).

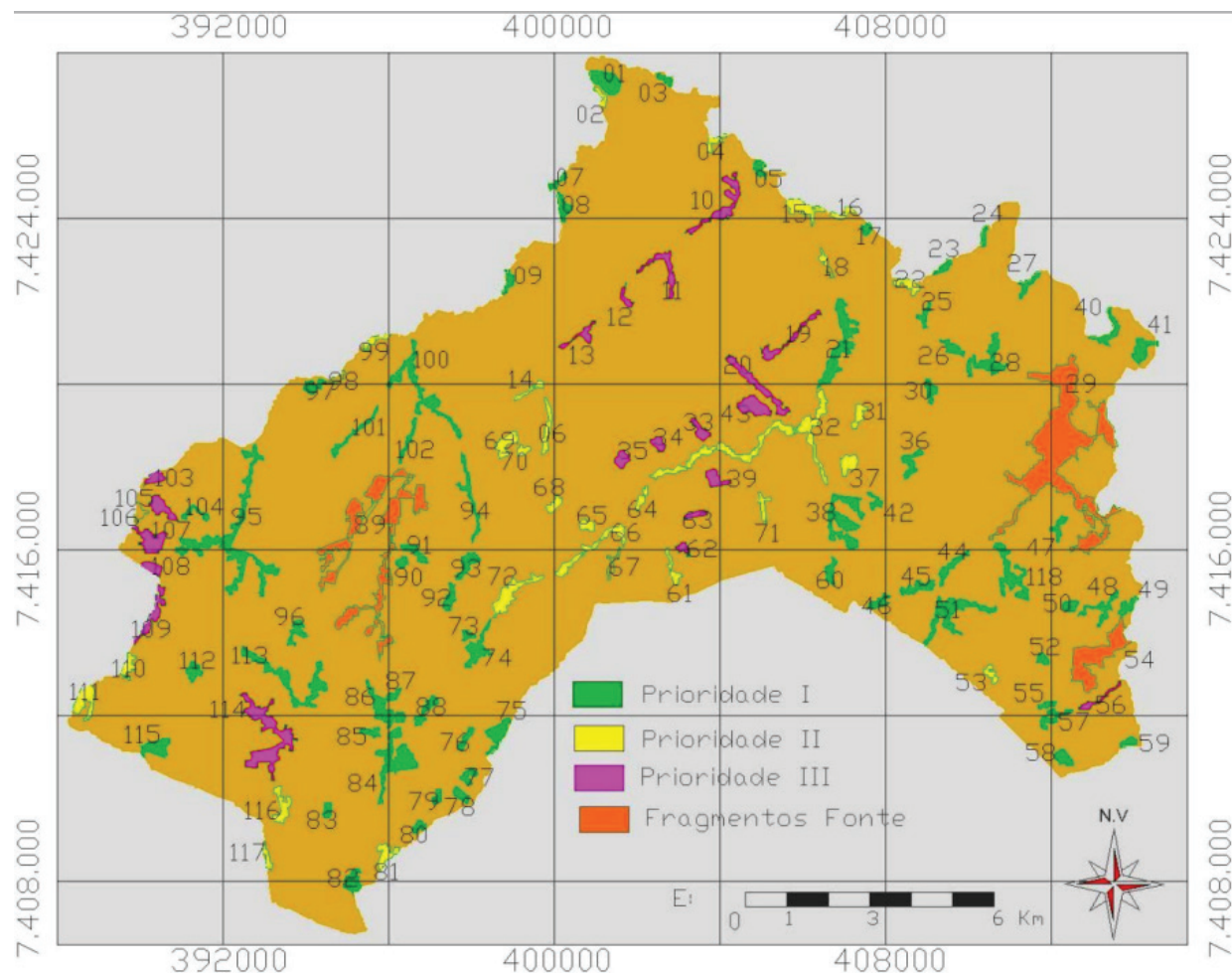

Figura 2. Classificação de prioridade para conservação dos fragmentos gerais do setor rural norte de Maringá 


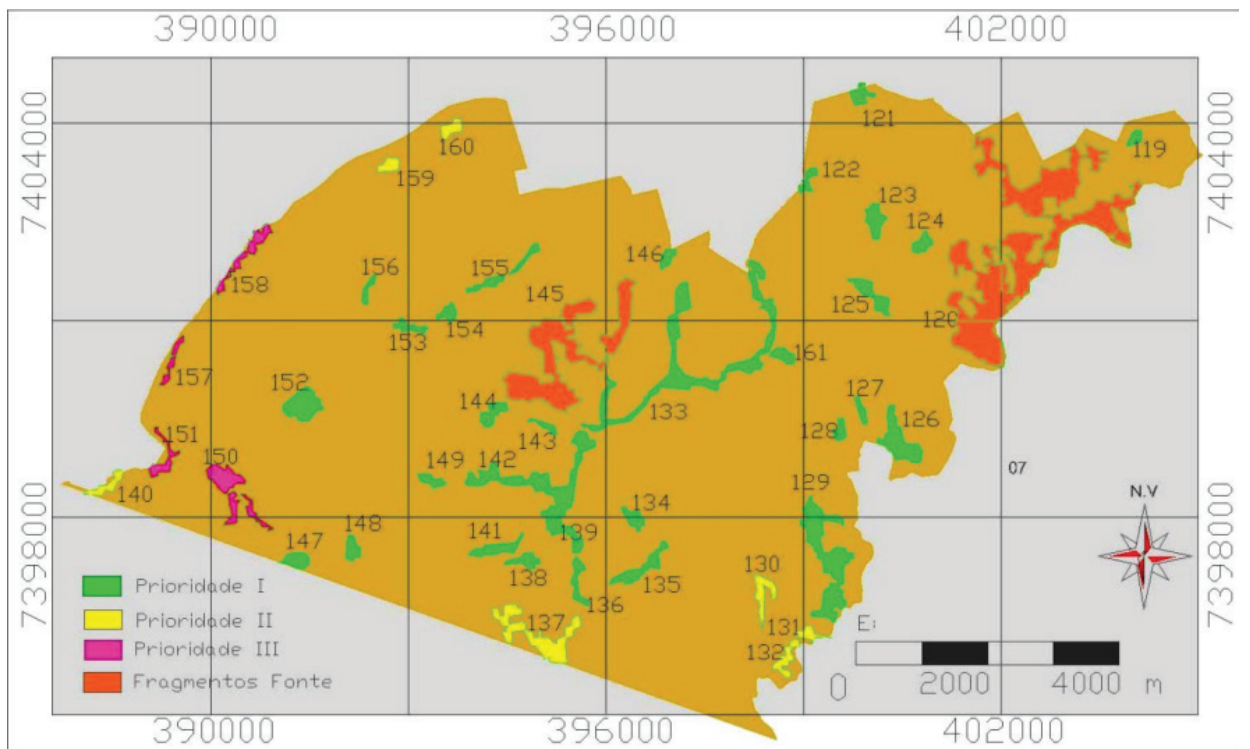

Figura 3. Classificação de prioridade para conservação dos fragmentos gerais do setor rural sul de Maringá

A cobertura florestal da área rural do município é considerada crítica pelos estudos em ecologia da paisagem, ficando abaixo dos limiares de percolação e conectividade. Stauffer (1985) chegou ao limiar de 59,28\%. Seus trabalhos indicam que acima desse limiar as paisagens se mostram mais conectadas e com grandes manchas de habitats. O limiar de aproximadamente 30\% verificado por Andrén (1994) e Fahrig (2003), mais usual em pesquisas em paisagens perturbadas, indica que acima desse as perdas de diversidade biológica ficam associadas a perdas de habitats, quando abaixo a distribuição espacial das "manchas" de habitats também contribui. De acordo com Metzger (2010), o limiar de 30\% seria funcional como um limite mínimo de cobertura nativa que uma paisagem antropizada deveria ter, pois permitiria conciliar o uso econômico e a conservação biológica.

Esses limiares não são unânimes e nem sempre há suporte empírico para eles, em zonas tropicais ainda são bastante criticados. Porém, há claras evidências, inclusive obtidas recentemente no Brasil, que paisagens com menos de 30\% de habitat tendem a ter fragmentos pequenos e muito isolados, e suportam por consequência comunidades muito empobrecidas, e isso para diferentes grupos taxonômicos (METZGER et al., 2009). 
Em relação ao tamanho dos fragmentos das paisagens em ambos os casos ocorre uma porcentagem muito grande de fragmentos pequenos (Tabelas 2 e 3 ).

Tabela 2. Classificação dos fragmentos florestais quanto ao tamanho na paisagem rural do setor norte

\begin{tabular}{cccc}
\hline $\begin{array}{c}\text { Classe de tamanho } \\
\text { (ha) }\end{array}$ & $\begin{array}{c}\text { Quantidade de } \\
\text { fragmentos }\end{array}$ & $\begin{array}{c}\text { Área ocupada } \\
\text { (ha) }\end{array}$ & $\begin{array}{c}\text { \% de ocupação na } \\
\text { paisagem }\end{array}$ \\
\hline$<50$ & 109 & 1535,0 & 59,1 \\
50,1 até 100 & 7 & 518,4 & 19,9 \\
100,1 até 200 & 1 & 196,1 & 7,5 \\
$>200$ & 1 & 349,8 & 13,5 \\
\hline Total & 118 & 2599,3 & 100,0 \\
\hline
\end{tabular}

Tabela 3. Classificação dos fragmentos florestais quanto ao tamanho na paisagem rural do setor sul

\begin{tabular}{cccc}
\hline $\begin{array}{c}\text { Classe de tamanho } \\
\text { (ha) }\end{array}$ & $\begin{array}{c}\text { Quantidade de } \\
\text { fragmentos }\end{array}$ & $\begin{array}{c}\text { Área ocupada } \\
\text { (ha) }\end{array}$ & $\begin{array}{c}\text { \% de ocupação na } \\
\text { paisagem }\end{array}$ \\
\hline$<50$ & 39 & 383,6 & 42,6 \\
50,1 até 100 & 2 & 122,8 & 13,6 \\
100,1 até 200 & 1 & 118,2 & 13,1 \\
$>200$ & 1 & 276,5 & 30,7 \\
\hline Total & 43 & 901,1 & 100,0 \\
\hline
\end{tabular}

Normalmente os fragmentos pequenos ficam sujeitos a um efeito de borda mais amplo e a ter menor biodiversidade (RODRIGUES, 1993; BENDER et al., 1998). Segundo Fernandez (2000), eles não são viáveis a médio e longo prazo pela ação drástica do efeito de borda, do impedimento da expansão de território (ocasionado pela matriz) e da ação de colonização das espécies pioneiras. São áreas com predisposição de se autoextinguirem com o passar do tempo. Porém, durante seu período de existência podem colaborar contendo espécies chaves e servindo como auxílio no deslocamento de várias espécies. Por isso são comumente denominados 
de "Steping Stones". Metzger (1997) cita que fragmentos com área superior a 0,72 hectares têm condições de assumir importante função na conexão florestal (Steping Stones), visto serem úteis à locomoção de animais e dispersão de sementes na paisagem.

Fator importante de ressaltar é que mesmo os fragmentos maiores da paisagem rural de Maringá possuem uma área considerada pouco efetiva nas funções gerais para conservação da biodiversidade. Segundo Valente (2001), os fragmentos que teriam condições de servirem de fonte de espécies são aqueles maiores que $500 \mathrm{ha}$, pois se considera que possam ter uma capacidade maior de se manterem estáveis com o passar do tempo, principalmente em relação à estrutura florestal. $\mathrm{O}$ maior fragmento florestal de Maringá (349,8 hectares - fragmento 29) apresenta área menor que os 500 ha citados, além disso, possui discretas estradas rurais que o cruzam, aumentando a fragmentação do que deveria ser o mais importante fragmento "fonte" de Maringá.

Os cinco fragmentos com maior área central (core) foram determinados nesta pesquisa como fragmentos "fonte" (Fragmentos 29, 54, 89, 120 e 145) isso se deu pelo fato de que não existem fragmentos maiores que 500 hectares na paisagem e pelo motivo de que na situação drástica de fragmentação da paisagem em questão, mesmo o menor fragmento dentre os maiores pode conter mais espécies do que um fragmento grande, apesar de ter a predisposição de não sustentar elas por um longo período (SIMBERLOFF; ABELE 1976; 1982; DIAMOND, 1976). De acordo com Di Bittetti et al. (2003), fragmentos de aproximadamente 100 ha de floresta tropical úmida, tem demonstrado potencial para perda de diversidade de um número substancial de espécies de pássaros de sub-bosque, pois se verificou em uma análise de duas décadas que esses diminuíram sua presença em fragmentos isolados.

Em termos de conectividade é possível observar que a paisagem norte não percola, ou seja, não contém floresta suficiente para se expandir ao ponto de cruzar a paisagem de um lado para o outro (da esquerda para a direita ou de cima para baixo). Essa capacidade de percolação poderá ser atingida no futuro por meio da formação dos denominados corredores ecológicos, formados pela recuperação das matas ciliares.

$\mathrm{Na}$ paisagem sul, apesar da conectividade entre fragmentos e uma PLAND baixa, pode-se dizer que a paisagem percola por meio das matas ciliares existentes 
no setor central, que se expandem de norte a sul (de cima para baixo), cruzando a paisagem. Esse resultado condiz com estudos de Metzger (2003) que diz que a nem sempre a percolação indica alta conectividade. Importante ressaltar que a percolação acontece, porém, não se estendendo muito em área, pois quando olhamos a continuidade da paisagem fora dos limites do município é possível observar a sequência de matas ciliares desconexas e estreitas.

O fato de existir percolação não indica que o trânsito de animais pela paisagem seja efetivo por completo, pois a qualidade (diversidade biológica, estágio sucessional e outras características) e o tamanho dos fragmentos ou corredores irão influir muito nas espécies capazes de cruzar a paisagem.

Foi possível verificar que os fragmentos de florestas (habitat) estão de forma geral dispersos e isolados nas paisagens (norte e sul). Com isso, ressalta-se uma predisposição das espécies da fauna a serem influenciadas por essa disposição espacial, e não necessariamente apenas pelo tamanho de suas áreas ocupadas na paisagem (WANDEMBRUCK, 2007).

As médias de distância dos fragmentos menores até os fragmentos fonte foram de 3.464 metros na paisagem norte e de 2.095 metros para a paisagem sul. Estas são as distâncias médias que um determinado animal teria de percorrer para atingir um remanescente com maior disponibilidade de alimento (diversidade) e até mesmo água, distância que deverá ser percorrida cruzando áreas de agricultura anual principalmente, existindo apenas, na maioria dos casos, "steping stones" para facilitar a jornada.

Essa realidade da paisagem faz com que um animal com estreita capacidade perceptual tenha um risco de mortalidade aumentado, pois terá de gastar mais tempo procurando um habitat favorável que um animal com uma distância de capacidade perceptual ampla. Animais de maior mobilidade, como aves e animais de grande porte em geral, terão maior capacidade de cruzar a paisagem, mas o entorno antropizado com agricultura e os trechos com rodovias e até mesmo urbanização irão dificultar essa movimentação (FORERO-MEDINA; VIEIRA, 2007). 


\section{CONCLUSÕES}

A execução das primeiras etapas do protocolo proposto demonstrou resultados significativos, obtendo uma classificação dos fragmentos de maior relevância para a conservação da paisagem. Indica-se para os fragmentos de maior prioridade ações como execução de estudos de diagnóstico e monitoramento de flora e fauna, prognósticos de ações de recuperação, enriquecimento florestal e conservação em geral.

A paisagem da área rural de Maringá se mostrou com pequena cobertura florestal e alta fragmentação, colaborando para a continuidade de uma queda da qualidade ambiental e da biodiversidade da região.

Na sequência pretende-se elaborar a última etapa do protocolo proposto, avaliando os fragmentos fonte determinados neste trabalho. Nesta futura análise serão considerados todos os atributos indicados na metodologia, e se completará a indicação dos fragmentos de prioridade para ações para conservação ambiental na paisagem rural do município de Maringá.

\section{REFERÊNCIAS}

ANDRÉN H, Effects of habitat fragmentation on birds and mammals in landscapes with different proportions of suitable habitat: a review. OIKOS, v. 71, p. 355-366, 1994.

BARROS, Z. X.; TORNERO, M. T.; STIPP, N. A. F.; CARDOSO, L. G.; POLLO R. A. Estudo da adequação do uso do solo, no município de Maringá - PR, utilizando-se de Geoprocessamento. ENGENHARIA AGRíCOLA, Jaboticabal, v.24, n.2, p.436-444, maio/ago. 2004. Disponível em: < http://www.scielo.br/pdf/eagri/v24n2/v24n2a24. pdf> Acesso em: 28 abr. 2010.

BENDER, D.J.; CONTRERAS, T.A.; FAHRIG,L. Habitat loss and population decline: a metaanalysis of patch size effect. ECOLOGY, v. 79,n. 2, p.517-533, 1998.

BIERREGAARD, R.O.; LOVEJOY, T.E. Birds in Amazonian forest fragments: effects 
of insularization, 1579. In: CONGRESSO INTERNACIONAL DE ORNITOLOGIA, 19., 1988. Anais... University of Ottawa, Ottawa, 1988.. p. 1564.

BLUM, C. T.; OLIVEIRA, R. D. Reserva Florestal Legal no Paraná, alternativas de recuperação e utilização sustentável. Boletim do Instituto Brasileiro da Qualidade e Produtividade no Paraná, v. 3, n. 10, 2003.

CASTELLA, P.R.; R.M. BRITEZ. A floresta com araucária no Paraná: conservação e diagnóstico dos remanescentes florestais. Brasília: Ministério do Meio Ambiente, 2004. 236p.

DI BITETTI M.S.; PLACCI, G.; DIETZ, L.A. Uma visão de Biodiversidade para a Ecorregião Florestas do Alto Paraná - Bioma Mata Atlântica: planejando a paisagem de conservação da biodiversidade e estabelecendo prioridades para ações de conservação. Washington, D.C.: World Wildlife Fund, 2003.

DIAMOND, J. M. Island biogeography and conservation: strategy and limitations. SCIENCE, v. 193, p. 1027-1029, 1976.

DURIGAN, G. et al. Estrutura e diversidade de componente arbóreo da floresta na Estação Ecológica de Caetetus, Gália, SP. Revista Brasileira de Botânica, São Paulo, v. 23, n. 2, p. 369-381, 2000.

DURIGAN, G. et al. Seleção de fragmentos prioritários para a criação de unidades de conservação do cerrado no Estado de São Paulo. Rev. Inst. Flor., São Paulo, v. 18, p. 23-37, 2006.

FAHRIG, L. Effects of habitat fragmentation on biodiversity. Annual Review of Ecology, Evolution and Systematic, v. 34, p. 487-515, 2003.

FERNANDEZ, F. A. S. O poema imperfeito: crônicas de biologia, conservação da natureza, e seus heróis. Curitiba: Ed. da UFPR, 2000.

FORERO-MEDINA, G.; VIEIRA, M. V. Conectividade funcional e a importância da interação organismo - paisagem. OECOL. BRAS., v. 11, n. 4, p. 493-502, 2007. 
FUNDAÇÃO SOS MATA ATLÂNTICA. Instituto Nacional de Pesquisas Espaciais. Atlas dos Remanescentes Florestais da Mata Atlântica - Período 2005-2008. Relatório Parcial. São Paulo, 2009. Disponível em: < <ttp://mapas.sosma.org.br/site_media/ download/atlas\%20mata\%20atlantica-relatorio2005-2008.pdf > Acesso em: 28 abr. 2009.

FUNDAÇÃO SOS MATA ATLÂNTICA. Instituto Nacional de Pesquisas Espaciais. Atlas dos remanescentes florestais da Mata Atlântica - período 2011-2012. São Paulo. 2012.

IBGE. Manual técnico da vegetação brasileira: sistema fitogeográfico, inventário das formações florestais e campestres, técnicas e manejo de coleções botânicas, procedimentos para mapeamentos. 2. ed. Rio de Janeiro: IBGE-Instituto Brasileiro de Geografia e Estatística, 2012. 275p.

LOVEJOY, T. E.; BIERRGAARD, R.O., RANKIN, J.M.; SCHUBART, H.R.O. Ecological dynamics of tropical forest fragments. In: SUTTON, S.L.; HITMORE, T.C.; CHADWICK, A.C. (Ed.). Tropical rain forest: ecology and management. Oxford: Blackwell Sci. Publ., 1983. (Special publication number 2 of the Brithish Ecological Society). p. 377-384.

MAACK, R. Geografia física do Estado do Paraná. Curitiba: M. Roesner, 1968. 350 p.

MAC ARTHUR, R. H.; WILSON, E. O. The theory of island biogeography. Princeton: Princeton University Press, 1967. 224 p.

MATOS, W. H. de. Fragmentos Florestais em Londrina, Paraná: qualidade ambiental e conservacão. Londrina. 2006. 127f. Dissertação (Mestrado em Geografia, Meio Ambiente e Planejamento) - Universidade Estadual de Londrina, Londrina, PR.

METZGER J. P.; DÉCAMPS, H. The structural connectivity threshold: an hypothesis in conservation biology at the landscape scale. Acta Ecologica, v. 18, p. 1-12, 1997.

METZGER, J. P. O que é ecologia da paisagem? Biota Neotropica - Revista 
Eletrônica. 2001. Disponível em: <http://biota.org.br.> Acesso em: 15 set. 2010.

METZGER, J. P. 2010. O código florestal tem base científica? Natureza e Conservação, v. 8, n. 1, p. 1-5, 2010. Disponível em: < http://quiprona.files.wordpress.com/2010/08/ o-codigo-florestal-tem-base-cientifica.pdf $>$ Acesso em: 10 out. 2010.

METZGER, J. P. Estrutura da paisagem e fragmentação: análise bibliográfica. Anais da Academia Brasileira de Ciências, v. 71, n. 3-I, p. 445-463, 1999.

METZGER, J. P. Estrutura da paisagem: o uso adequado de métricas. In: JÚNIOR, L. C.; VALLADARES-PADUA, C.; RUDRAN, C. (Ed). Métodos de estudos em biologia da conservação e manejo da vida silvestre. Curitiba: UFPR, 2003, p. 435-453

NOSS, R. F.; CSUTI, B. Habitat fragmentation. In: MEFFE, G. K.; CARROL, C. R. (Ed). Principles of conservation biology. Sunderland: Sinauer Associates, 1997. p. 269304.

PRIMACK, R. B.; RODRIGUES, E. Biologia da conservação. Londrina: E. Rodrigues, 2001. $328 \mathrm{p}$.

RODRIGUES, E. Ecologia de fragmentos florestais no gradiente de urbanização de Londrina - PR. 1993.102f. Dissertação (Mestrado) - Escola de Engenharia de São Carlos, Universidade de São Paulo, São Carlos, SP.

SIMBERLOFF, D.; ABELE, L.G. Refuge design and island biogeography theory: effects of fragmentation. American Naturalist, v. 120, p. 41-50, 1982.

STAUFFER, D. Introduction to percolation theory. London: Taylor e Francis, 1985.

VALENTE, R.O.A. Análise da estrutura da paisagem na bacia do Rio Corumbataí, SP. 2001. Dissertação (mestrado) - Escola Superior de Agricultura "Luiz de Queiróz". Piracicaba, São Paulo, SP.

VELOSO, H. P.; RANGEL FILHO, A.L.R.; LIMA, J.C.A. Classificação da vegetação brasileira, adaptada a um sistema universal. Rio de Janeiro: IBGE, Departamento 
de Recursos Naturais e Estudos Ambientais, 1991.

WANDEMBRUCK, A.; SVOLENSKI, A. C.; VIDOLIN, G. P. Relatório Final - Projeto Estudo da Paisagem. Distrito de Mocambo: Biositu-Projetos e Estudos Ambientais Ltda. 2007.

WILLIS, E.O. The composition ofavian communities in remanescent woodlots in southern Brazil. PAPS AVU!' ZOOL., São Paulo, v. 33, p. 1-25, 1979.

Recebido em: 2016-03-02 Aceito em: 2017-03-02 